\title{
Stable Bio-oil Production from Proteinaceous Cyanobacteria: \\ Tail Gas Reactive Pyrolysis of Spirulina \\ Supporting Information
}

Bruna M. E. Chagas ${ }^{1,2}$, Charles A. Mullen ${ }^{2}$, Christina Dorado ${ }^{2}$, Yassen Elkasabi ${ }^{2}$, Akwasi A. Boateng $*^{2}$, Marcus A.F. Melo ${ }^{1}$, Carlos H.Ataíde ${ }^{3}$

${ }^{1}$ Universidade Federal do Rio Grande do Norte, CT, Departamento de Engenharia Química, 59078-970, Natal/RN, Brazil m

${ }^{2}$ USDA-ARS, Eastern Regional Research Center, 600 E. Mermaid Lane, Wyndmoor, PA 19038, United States

${ }^{3}$ Universidade Federal de Uberlândia (UFU), Faculdade de Engenharia Quimica, Campus Santa Mônica, Bloco 1K, 38408-144 Uberlândia, MG, Brazil

*Corresponding author. E-mail: akwasi.boateng@ars.usda.gov

Mention of trade names or commercial products in this publication is solely for the purpose of providing specific information and does not imply recommendation or endorsement by the U.S. Department of Agriculture. USDA is an equal opportunity provider and employer. 


\section{Table S1}

Characterization of Spirulina used in this study.

\begin{tabular}{llll}
\hline Ultimate analysis (wt.\%, daf) & \multicolumn{3}{l}{ Proximate analysis (wt.\%) } \\
\hline $\mathrm{C}$ & 48.05 & Moisture & 5.60 \\
$\mathrm{H}$ & 7.04 & Ash & 7.94 \\
$\mathrm{~N}$ & 10.74 & Volatile matter & 79.38 \\
$\mathrm{~S}$ & 0.72 & Fixed Carbon & 5.28 \\
$\mathrm{O}^{\mathrm{a}}$ & 33.45 & HHV $(\mathrm{MJ} / \mathrm{kg})$ & 22.56 \\
\hline
\end{tabular}


Table S2

Identified nitrogen containing compounds in regular and TGRP pyrolysis of spirulina (\% area)

\begin{tabular}{|c|c|c|c|}
\hline \multirow[t]{2}{*}{ Compounds } & \multicolumn{2}{|c|}{$\%$ Area } & \multirow[t]{2}{*}{$\begin{array}{c}\text { Functional } \\
\text { group/structure }\end{array}$} \\
\hline & Regular $^{\mathrm{e}}$ & TGRP ${ }^{\mathbf{f}}$ & \\
\hline Nitriles $^{\mathrm{a}}$ & 5.8 & $9.5-11.4$ & $\mathrm{R}-\mathrm{C} \equiv \mathrm{N}$ \\
\hline Pyrroles $^{b}$ & 4.0 & $4.2-4.3$ & \\
\hline Amides $^{\mathrm{c}}$ & 13.0 & $9.7-11.0$ & \\
\hline Indoles $^{\mathrm{d}}$ & 8.2 & $10.3-11.9$ & \\
\hline 2,5-dimethylpiperazine & 8.5 & $\mathrm{Nd}$ & \\
\hline 2-Aminopyridine & 0.4 & 1.0 & \\
\hline 1,4-dimethylpyrazole & 0.7 & nd & \\
\hline 2,2,6,6 - Tetramethyl-4-piperidone & 3.9 & nd & \\
\hline 2,5-Pyrrolidinedione & 2.3 & nd & \\
\hline $\begin{array}{l}\text { 5-(2-methylpropyl)-2,4- } \\
\text { imidazoledinedione }\end{array}$ & 0.8 & nd & \\
\hline 5-oxoproline & 2.5 & nd & \\
\hline
\end{tabular}

${ }^{a}$ 4-methyl-pentanitrile, 3-methyl-butanitrile, benzonitrile, benzyl nitrile, benzenepropanenitrile, hexadecanenitrile

${ }^{\mathrm{b}}$ pyrrole, 3-methyl-1H-Pyrrole, hexahydropyrrolo[1,2- $\left.\alpha\right]$ pyrazine-1,4-dione

${ }^{\mathrm{c}}$ acetamide, propanamide, hexanamide, hexadecanamide, 3-methyl-butanamide

${ }^{\mathrm{d}}$ Indole, 3-methyl-1H-indole

${ }^{\mathrm{e}}$ Results from a single experiment

${ }^{\mathrm{f}}$ Experiments conducted in duplicate 


\section{NMR Analysis of ESP Oils and Condensers' Organic Fraction}

Carbon $13\left({ }^{13} \mathrm{C}\right)$ Nuclear Magnetic Resonance Spectroscopy (NMR) and Proton $\left({ }^{1} \mathrm{H}\right)$ NMR were conducted on the ESP oils from the regular and tail-gas reactive pyrolysis of Spirulina as well as the condensers' organic fraction from the TGRP of Spirulina. Solution-state NMR spectra were recorded at $9.4 \mathrm{~T}$ on a Varian Inova NMR spectrometer (Palo Alto, CA) using a $5 \mathrm{~mm}$ dual broad-band probe equipped with $\mathrm{z}$-axis pulsed field gradients or on a $14 \mathrm{~T}$ Agilent VNMRS NMR spectrometer (Santa Clara, CA) using a 5 mm One NMR probe with z-axis pulsed field gradients. All spectra were acquired at $40{ }^{\circ} \mathrm{C}$ in $\mathrm{CD}_{3} \mathrm{OD}$. The ${ }^{1} \mathrm{H}$ NMR spectra, at 400 $\mathrm{MHz}$, had a spectral width of $13 \mathrm{ppm}$ and were acquired with a $45^{\circ}$ pulse angle with a 6 s relaxation delay and were referenced to the sodium salt of 3-(trimethylsilyl)propionic acid- $\mathrm{d}_{4}$ (TSP). All ${ }^{13} \mathrm{C}$ NMR spectra had a sprectral width of $250 \mathrm{ppm}$, were acquired using a $45^{\circ}$ pulse angle, inverse-gating, and were referenced to the solvent ${ }^{13} \mathrm{C}$ peak. Reasonable signal-to-noise was achieved with 15,000-70,000 transients, utilizing a 4 or $6 \mathrm{~s}$ relaxation delay to provide adequate recovery of the signal for integration purposes. All data processing was performed using Spinworks4 (Version 4.1.0.0) (Copyright 2015, Kirk Marat, University of Manitoba (ftp://davinci.chem.umanitoba.ca/pub/marat/SpinWorks/). 


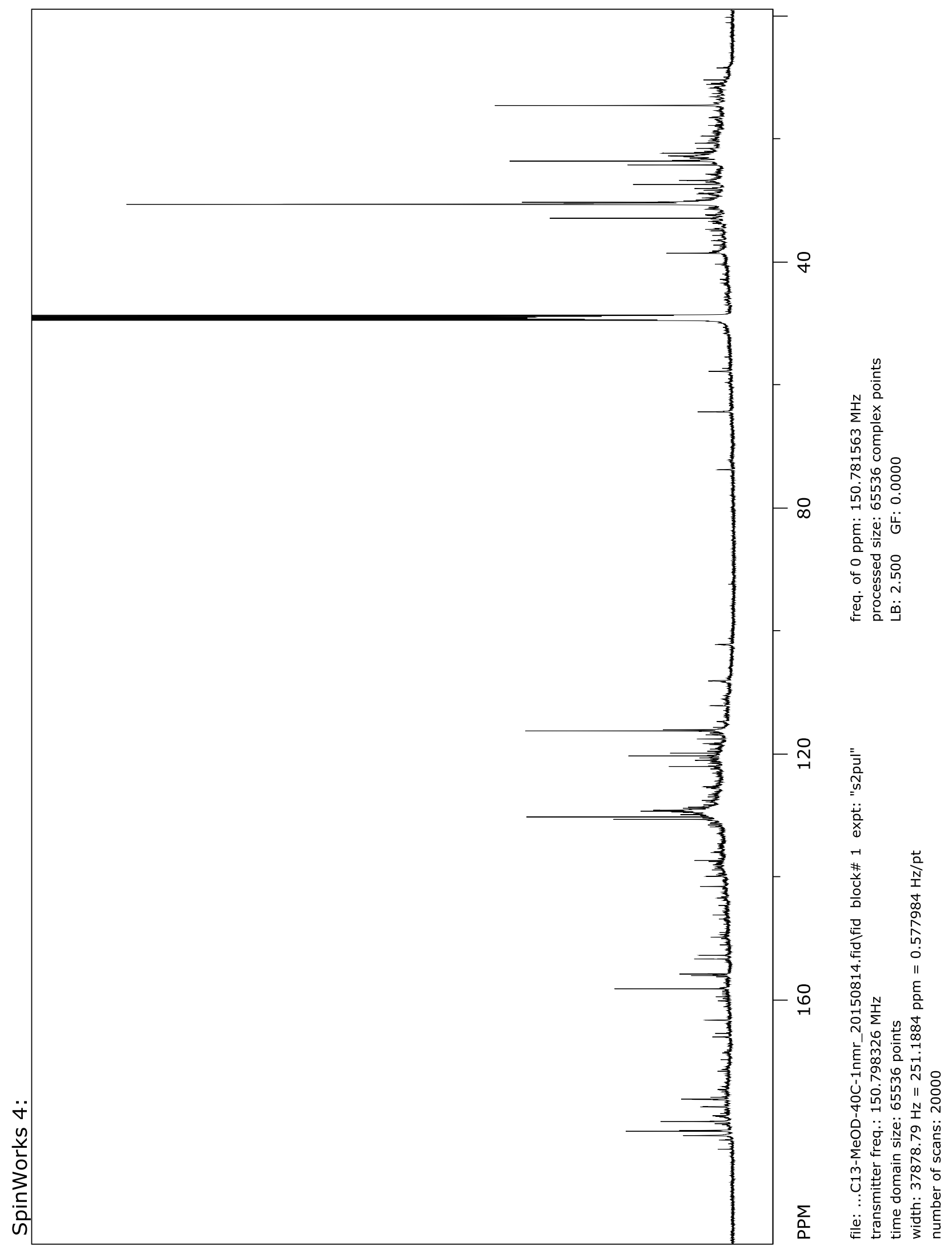

Figure S1. ${ }^{13} \mathrm{C}$ NMR of ESP oil from the Regular Pyrolysis of Spirulina recorded at a frequency of $150 \mathrm{MHz}$ in Deuterated Methanol 


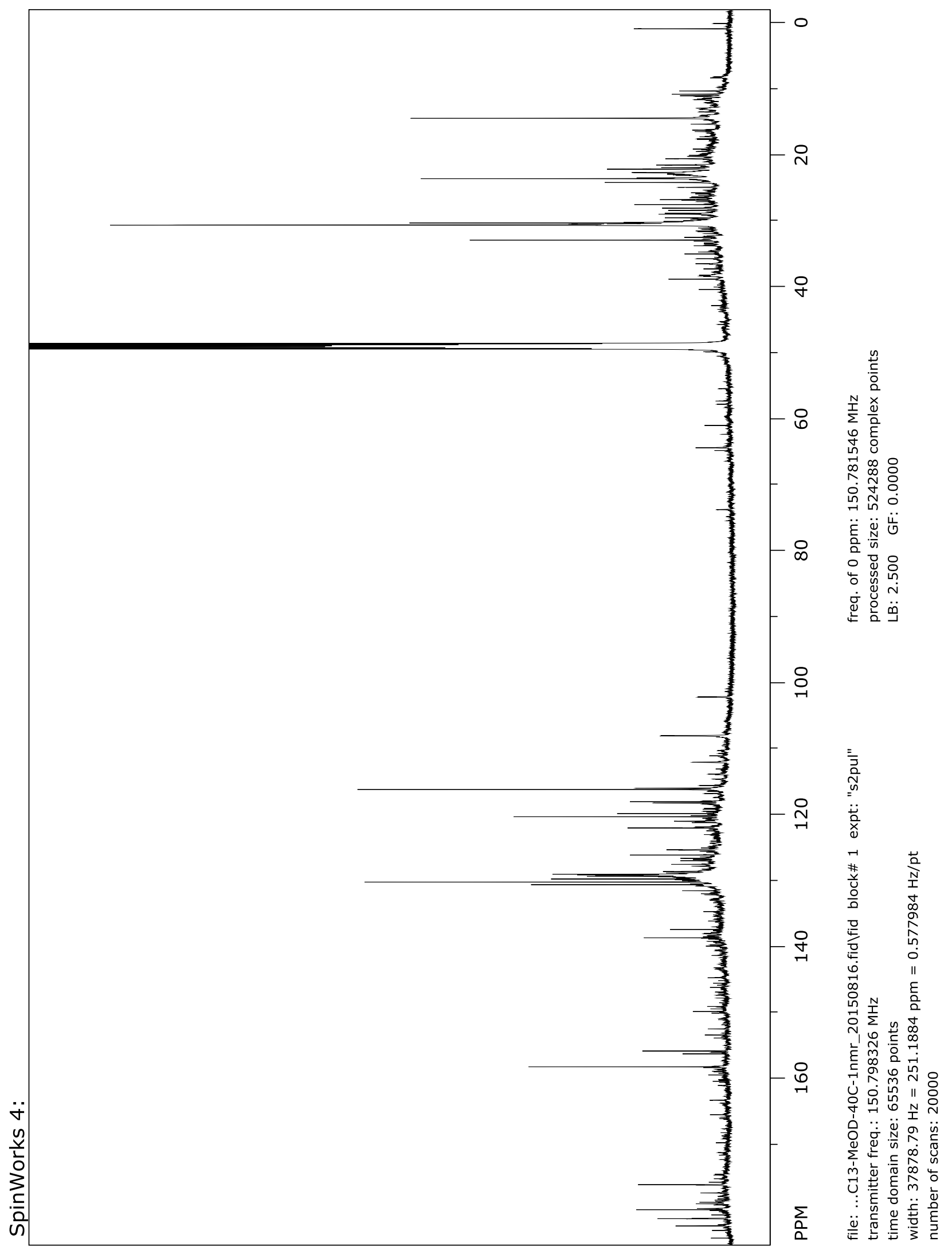

Figure S2. ${ }^{13} \mathrm{C}$ NMR of ESP oil from the TGRP of Spirulina recorded at a frequency of $150 \mathrm{MHz}$ in Deuterated Methanol 


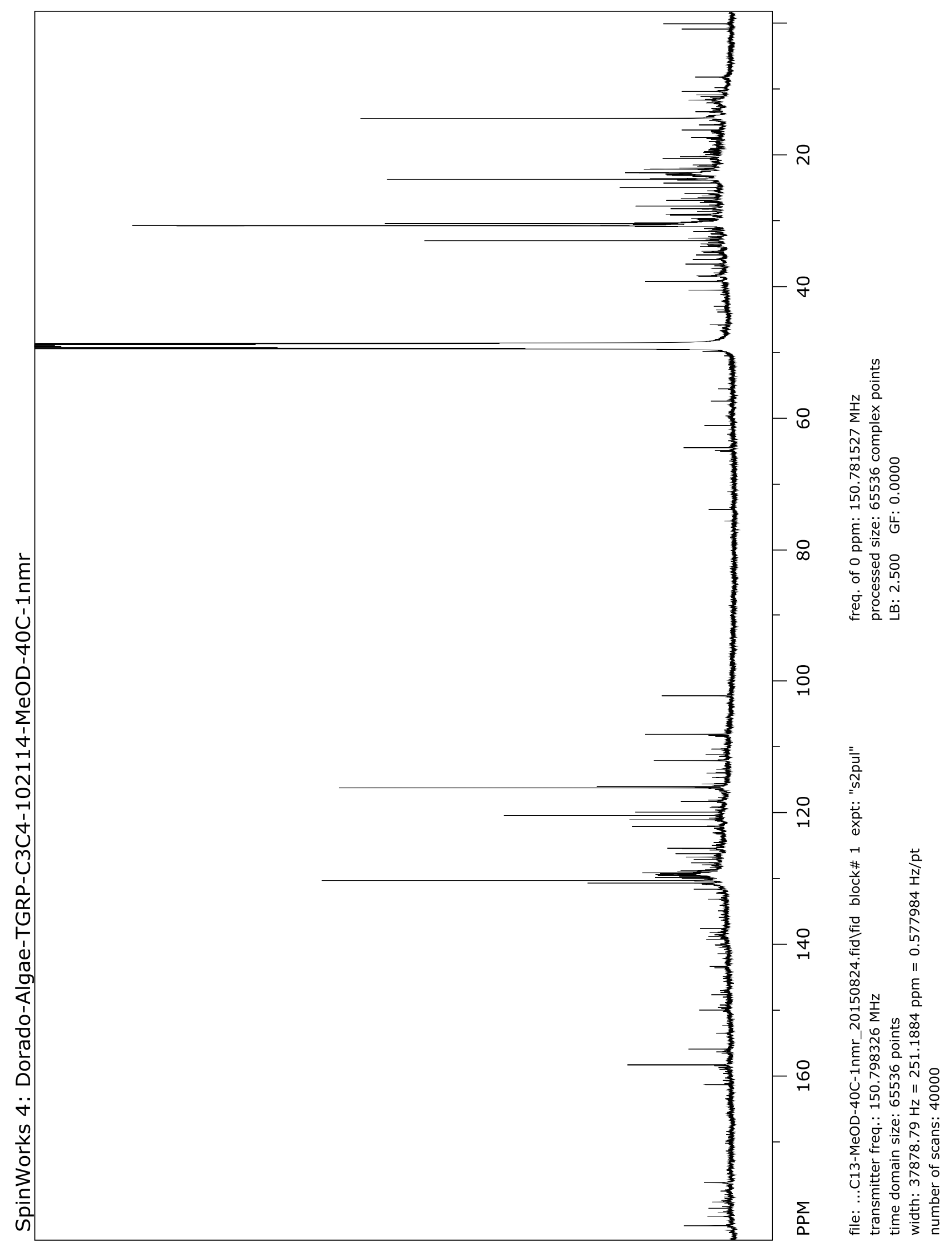

Figure S3. ${ }^{13} \mathrm{C}$ NMR of the Condensers' Organic Fraction from the TGRP of Spirulina recorded at a frequency of $150 \mathrm{Mz}$ in Deuterated Methanol 


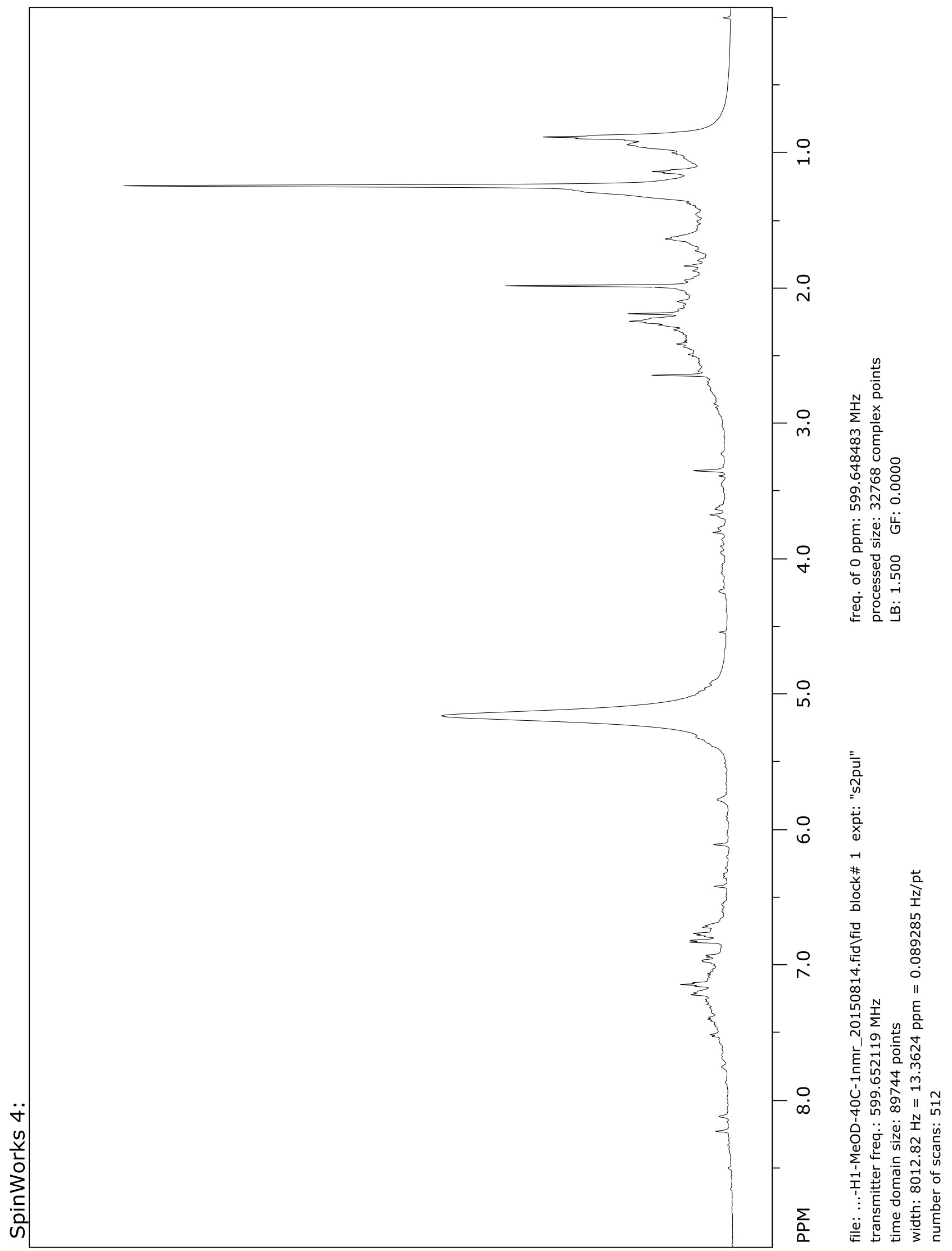

Figure

S4. ${ }^{1} \mathrm{H}$ NMR of the ESP oil from the Regular Pyrolysis of Spirulina recorded at a frequency of $600 \mathrm{MHz}$ in Deuterated Methanol 


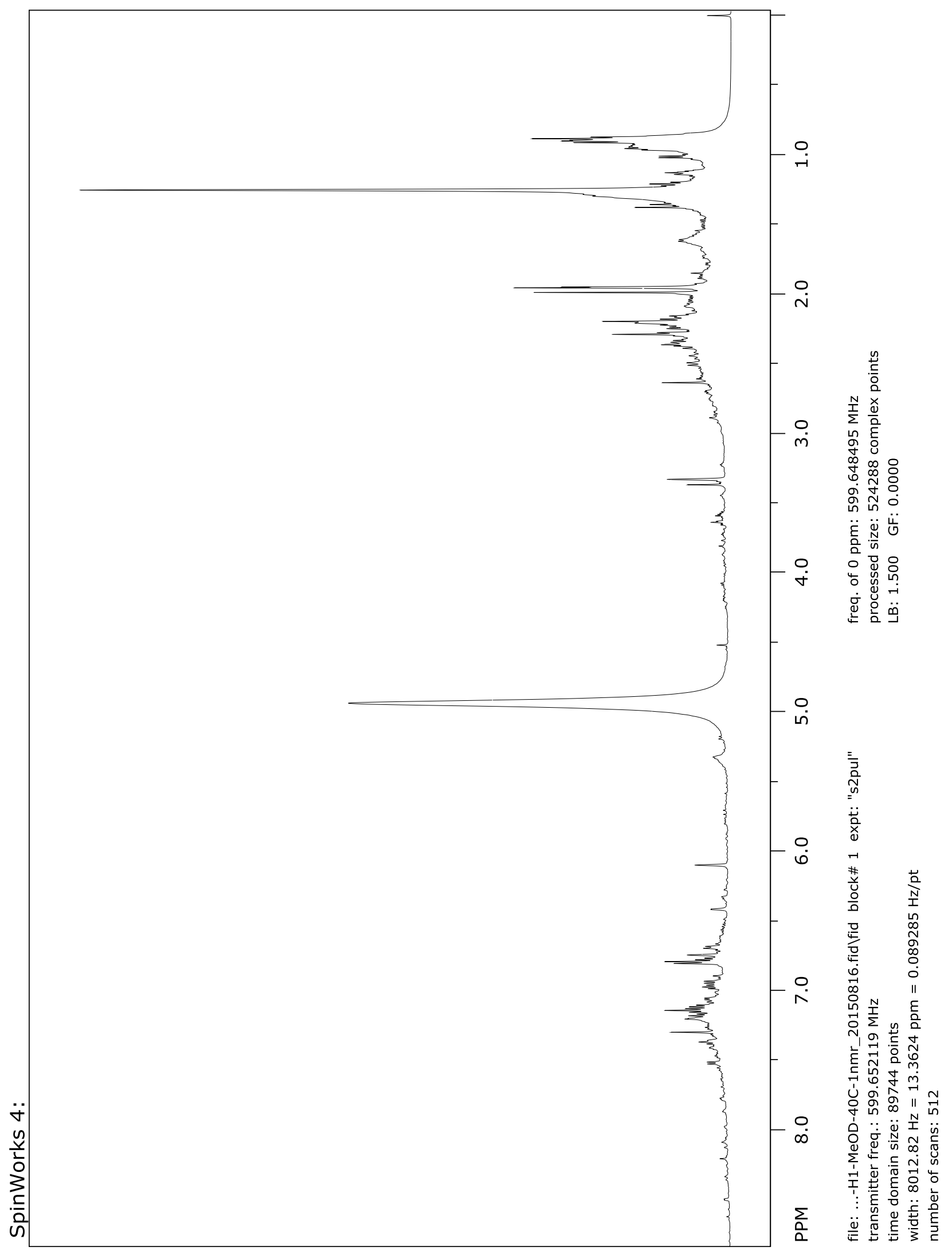

Figure S5. ${ }^{1} \mathrm{H}$ NMR of the ESP oil from the TGRP of Spirulina recorded at a frequency of $600 \mathrm{MHz}$ in Deuterated Methanol 


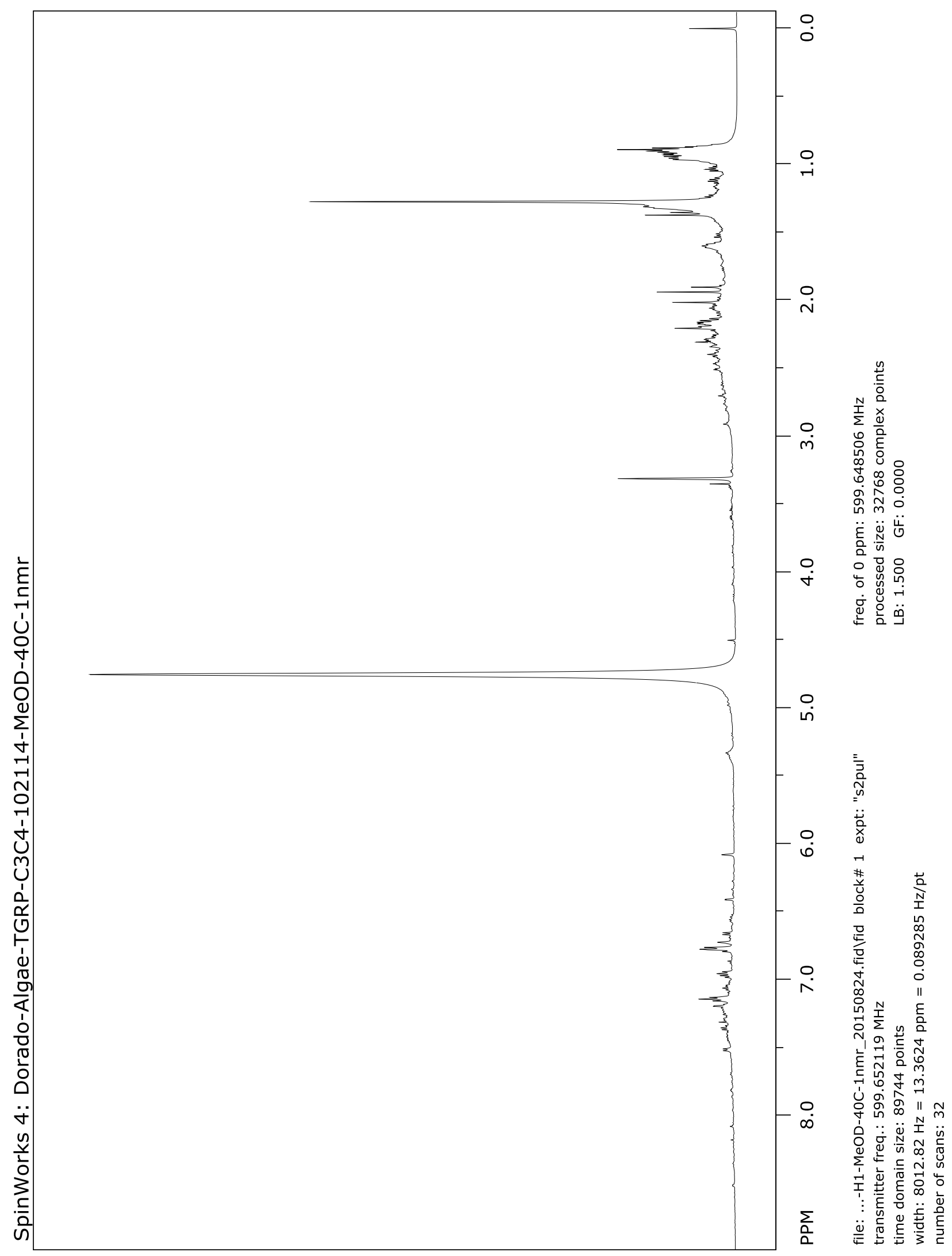

Figure S6. ${ }^{1} \mathrm{H}$ NMR of the Condensers' Organic Fraction from the TGRP of Spirulina recorded at a frequency of $600 \mathrm{MHz}$ in Deuterated Methanol 


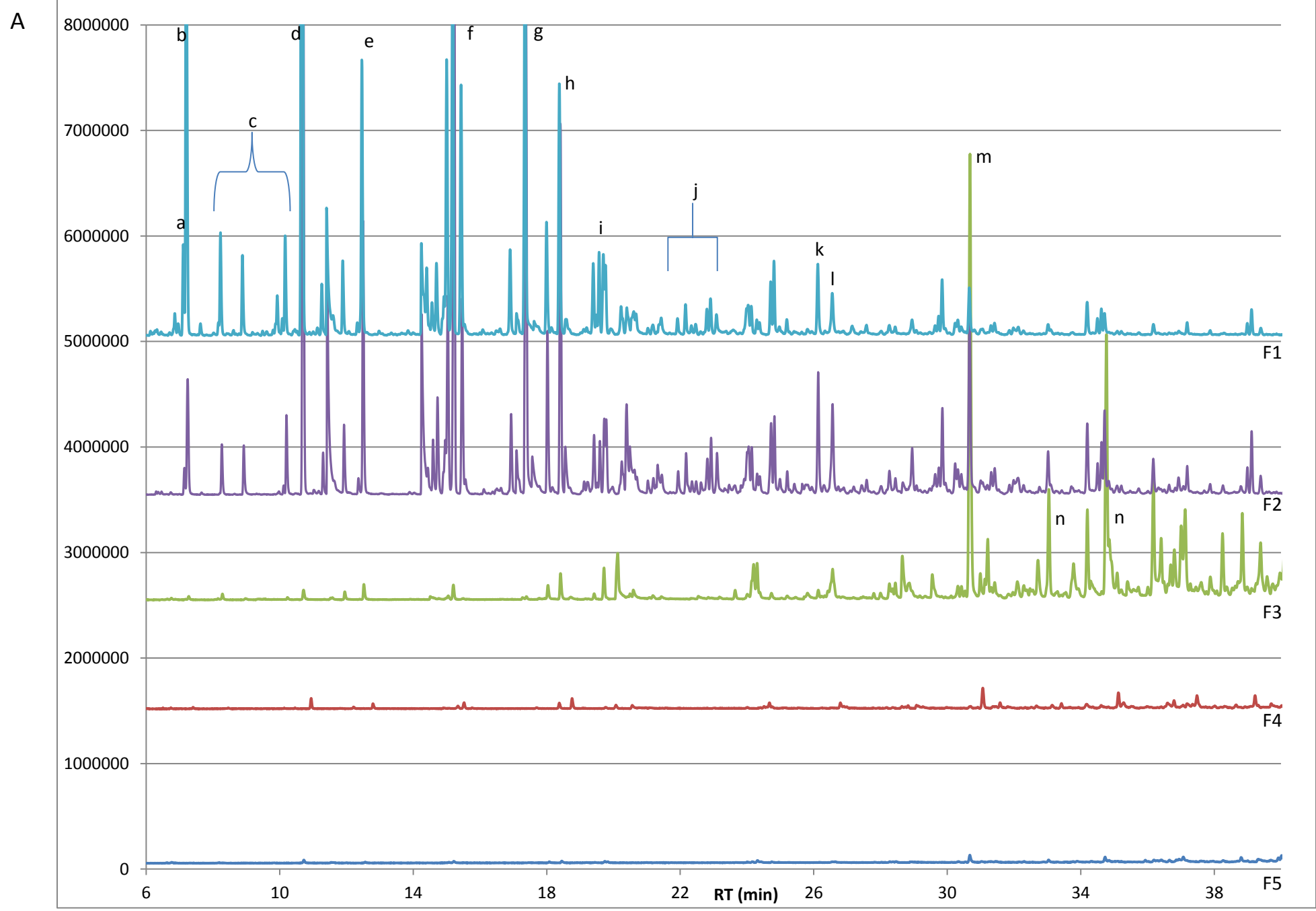




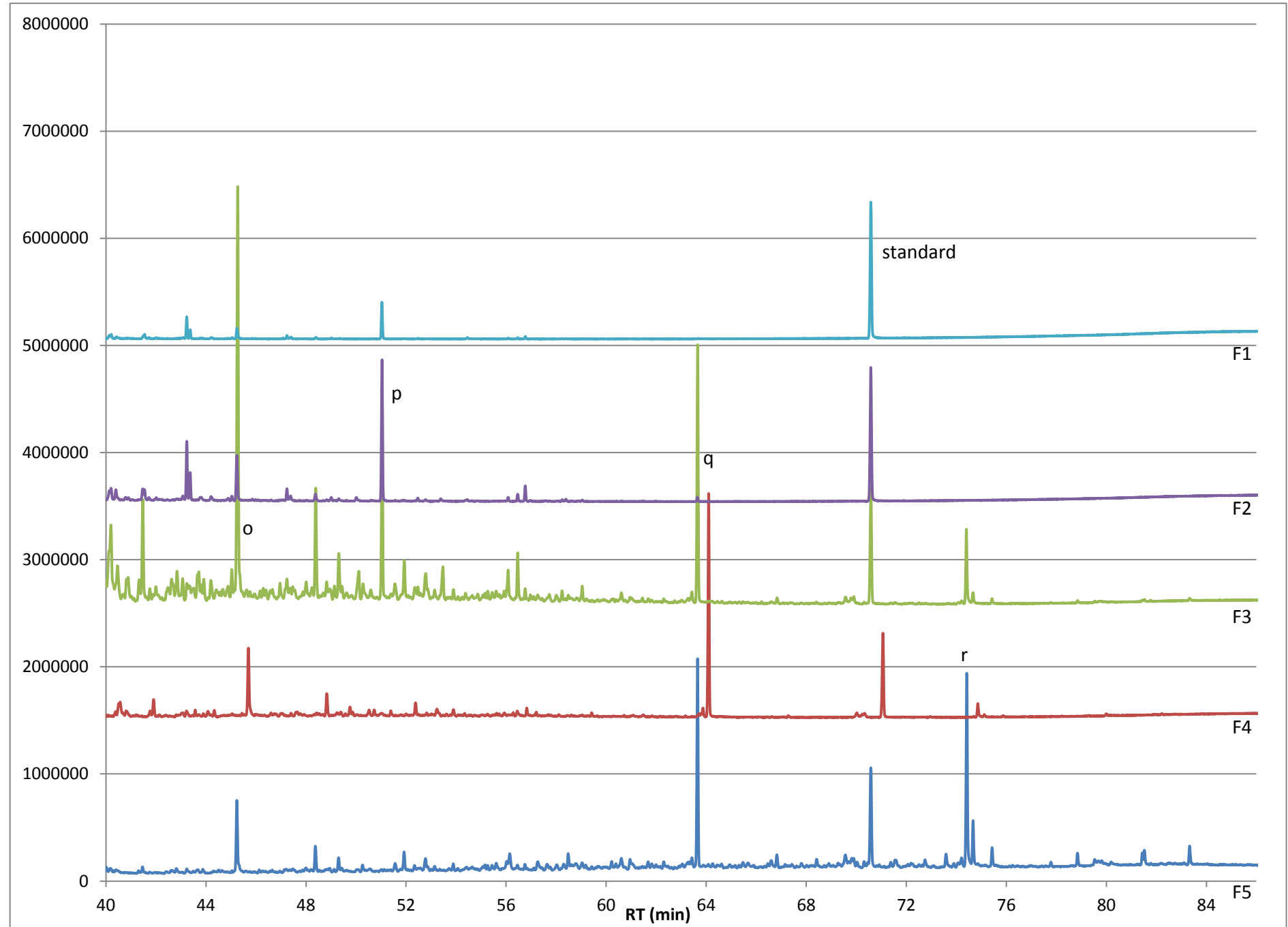

Figure S7. GC/MS Chromatograms of distillate fractions from Spirulina TGRP bio-oil. a. propenitrile b. benzene c. C4-nitriles d. toluene e. p-xylene f. pyrrole g. styrene h. pentenitrile i. dimethyl pyridines $\mathrm{j}$. $\mathrm{C} 3$-alkyl benzenes $\mathrm{k}$. indene 1 . benzonitrile $\mathrm{m}$. phenol n. cresols o. indole p. hexadecane q. hexadecane nitrile r. hexdecanamide (A)Retention time 6-40 min (B) Retention time 40-85 min 


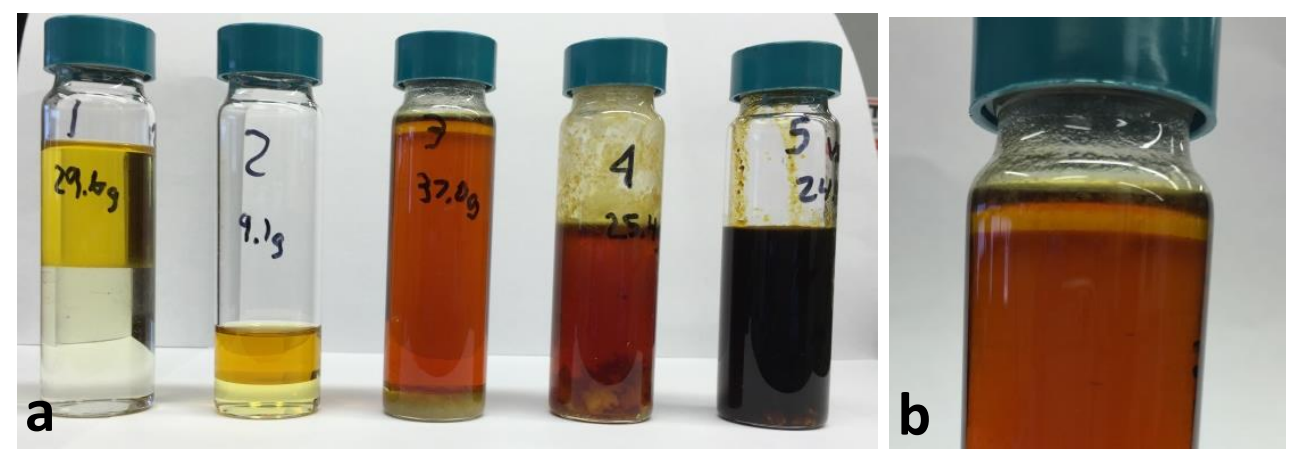

Figure S8 - (a) Spirulina TGRP bio-oil distillation fractions, with fraction 3 (b) exhibiting triphasic behavior. The top organic phase consisted primarily of hexadecane 